\title{
Altered expression of cytokeratins in primary, recurrent and syndrome keratocystic odontogenic tumors
}

\author{
Jean Nunes dos Santos • Gabriel Queiroz Vasconcelos Oliveira • \\ Clarissa Araújo Silva Gurgel - Renata Oliveira de Souza • Caroline Brandi Schlaepfer Sales • \\ Alberto de Aguiar Pires Valença Neto • Eduardo Antônio Gonçalves Ramos
}

Received: 20 September 2009/Accepted: 2 November 2009/Published online: 15 November 2009

(C) Springer Science+Business Media B.V. 2009

\begin{abstract}
Keratocystic odontogenic tumor (KOT) is a benign cystic tumor that affects the jaw bones and may be associated with the nevoid basal cell carcinoma syndrome (NBCCS). Twenty-five cases diagnosed as KOT, including primary and recurrent tumors and those associated with NBCCS, were submitted to immunohistochemical study for analysis of cytokeratins (CKs) 7, 8, 10, 13, 14, 18 and 19. The results showed CK13 immunostained on the intermediate layers and upper cells. CK14 was expressed in all epithelial layers and in those areas where inflammation and subepithelial splits were present; this protein was preserved within the basal cells. CK 18 was expressed mainly in the basal layer, whereas CK19 was expressed mainly on the intermediate and superficial layers. The remaining CKs tested were not immuoreactive. The status of maturation of cytokeratin seems to be altered on KOTs, and this is not distinct when different tumors are compared.
\end{abstract}

J. N. dos Santos · G. Q. V. Oliveira · R. O. de Souza .

C. B. S. Sales

Department of Oral Pathology, Laboratory of Oral Surgical Pathology, School of Dentistry, Federal University of Bahia, Salvador, Bahia, Brazil

C. A. S. Gurgel - E. A. G. Ramos

Laboratory of Pathology and Molecular Biology, Gonçalo Moniz Research Center, Oswaldo Cruz Foundation, Salvador, Bahia, Brazil

A. de Aguiar Pires Valença Neto

Laser Center, School of Dentistry, Federal University of Bahia,

Salvador, Bahia, Brazil

J. N. dos Santos $(\bowtie)$

Faculdade de Odontologia-UFBA, Avenida Araújo Pinho, 62,

Canela, Salvador, Bahia 40110-150, Brazil

e-mail: jeanunes@ufba.br; jeanunes@yahoo.com.br
Keywords Cytokeratin - Odontogenic Keratocysts · Odontogenic Neoplasms · Immunohistochemistry

\section{Introduction}

Keratocystic odontogenic tumor (KOT) is a benign cystic neoplasm that affects jaw bones, originated from dental lamina (Kolar et al. 2006) by disturbance on the PTCH gene (Gomez and Marco 2005; Hardcastle et al. 1999). It may be related to the nevoid basal cell carcinoma syndrome (NBCCS). It is characterized by multiple KOTs, predisposition to the development of basocellular carcinomas, palmar and plantar pits and ectopic calcifications (Ahn et al. 2004). Histologically, this tumor is composed of a cystic wall lined by thin, stratified squamous, parakeratinized epithelium, exhibiting palisade-like basal cells. Other features include satellite cysts and subepithelial splits. Inflammatory infiltrate may be also seen (El-Hajj and Anneroth 1996; González-Alva et al. 2008; Kolar et al. 2006; Lam and Chan 2000; Myoung et al. 2001; Meningaud et al. 2006; Ochsenius et al. 2007; Tortorici et al. 2008).

The cytokeratins (CK) are characteristic proteins from epithelium that belong to the group of the intermediate filaments (FIs) present in the cytoskeleton. There are 20 CKs catalogued, and they are classified as type I (acid, from 9 to 20) and type II (basic or neutral, from 1 to 8). Generally, they are expressed in the epithelium as a pair of proteins (heterodimers), being a basic and an acid protein (Chu and Weiss 2002; Cooper et al. 1985). These heterodimers are distributed as tetramers within the epithelium forming filamentous structures (Barak et al. 2004).

Each epithelial tissue shows a profile of cytokeratins, which are useful to their identification and immunophenotypical characterization (Moll et al. 1982; Moll et al. 
2008). Therefore, the study of the profile of CKs has become one of the main methods to recognize epithelial tumors, and to characterize a disordered epithelial maturation that might be occurring (Santos et al. 2003). The expression of these proteins depends on the type of epithelium (simple or stratified), differentiation and development status (Barak et al. 2004). In addition, the cellular differentiation determines alterations in the cellular components, such as proteins of cytoskeleton, which explains its influence on the expression of the CKs (Shuler and Shriver 1987). Thus, the status of maturation of the epithelium may be performed through the analysis of the expression of the cytokeratins.

The aim of our study was to describe and compare the status of epithelial maturation of KOTs, using cytokeratins $7,8,10,13,14,18$ and 19 in an attempt to distinguish sporadic and recurrent lesions and those associated with NBCCS.

\section{Materials and methods}

After Institutional Ethics Committee approval, 25 cases of KOTs were obtained from the Laboratory of Oral Surgical Pathology of School of Dentistry of the Federal University of Bahia. All of tumors were surgically removed, and they were represented by ten primary tumors, ten recurrent ones and five associated with NBCCS. The cases were selected considering previous anatomopathological reports.

All sections stained with hematoxylin and eosin were reassessed by an experienced pathologist using the 2005 World Health Organization criteria.

For immunohistochemical study, $3 \mu \mathrm{m}$ sections from formalin-fixed, paraffin-embedded tissues of all cases were obtained. To assess the status of maturation, cytokeratins (CKs 7, 8, 10, 13, 14, 18 and 19) were used. The primary monoclonal antibodies, dilution, incubation time, pretreatments, and source used are listed in Table 1. Briefly, tissue sections were deparaffinized, hydrated in a decreasing ethanol sequence and formalin pigment was removed with
$10 \%$ ammonium hydroxide in $95 \%$ ethanol. For CK 10 , prior to incubation with the primary antibody, the sections were treated with $1 \%$ tripsine, $\mathrm{pH} 7,8$, at $37^{\circ} \mathrm{C}$ for $30 \mathrm{~min}$. The sections were incubated with the primary antibodies at $4^{\circ} \mathrm{C}$, overnight in humid chamber. After washing in PBS, the sections were treated with labeled Streptavidin-Biotin System (LSAB, Dako Corporation, Carpinteria, USA). Diaminobenzidine (DAB, Dako, Corporation, Carpinteria, USA) was used as chromogen for $2-5 \mathrm{~min}$ at room temperature and counterstained with Harris hematoxylin for $10 \mathrm{~s}$ and coverslipped. Salivary gland and nevus were used as positive controls. Omission of the primary antibody was performed for negative control.

The immunohistochemistry was evaluated using criteria adapted from Stoll et al. (2005), and immunopositive cells were identified as a brown color irrespective of staining intensity. The distribution of the proteins was evaluated particularly on the basal, intermediate and upper, and superficial layers, regarding primary and recurrent tumors and those associated with NBCCS. Satellite cysts were also included.

\section{Results}

Twenty-five specimens were included in this study, being 13 men and 12 women with a mean age of 36.6 years $(\mathrm{SD} \pm 12.8)$. Ten lesions were primary, ten recurrent, and five associated with NBCCS. Histologically, the tumors showed parakeratinized epithelium exhibiting atrophy, superficial corrugation and basal cells arranged in palisade. Some cases showed subepithelial splits and epithelial buds and satellite cysts. In addition, discrete to significant mononuclear inflammatory infiltrate was seen in 14 (56\%) lesions. The histopathological features are summarized in Table 2.

The immunohistochemical assessment showed that the CKs 13 (primary tumors, 7/10; recurrent tumors, 6/10; syndrome tumors, 4/5), 14 (primary tumors, 10/10; recurrent tumors, 10/10; syndrome tumors, 5/5), 18 (primary
Table 1 Antibodies used and working protocol

\begin{tabular}{lllll}
\hline Antibodies & Clone and source & Dilution & Retrieval & $\begin{array}{l}\text { Incubation } \\
\text { time (min) }\end{array}$ \\
\hline CK7 & OV-TL12/30 (novocastra) & $1: 200$ & 10 mM Citrate buffer pH 6.02 & 60 \\
CK8 & NCL-TS1 (novocastra) & $1: 100$ & $10 \mathrm{mM}$ Citrate buffer pH 6.02 & 60 \\
CK10 & NCL-CK10 (novocastra) & $1: 50$ & $1 \%$ tripsine, pH 7, 8 & 60 \\
CK13 & NCL-CK13 (novocastra) & $1: 100$ & $10 \mathrm{mM}$ Citrate buffer pH 6.02 & 60 \\
CK14 & NCL-LL002 (novocastra) & $1: 20$ & $10 \mathrm{mM}$ Citrate buffer pH 6.02 & 60 \\
CK18 & NCL-CK18 (novocastra) & $1: 40$ & $10 \mathrm{mM}$ Citrate buffer pH 6.02 & 60 \\
CK19 & B170 (novocastra) & $1: 100$ & $10 \mathrm{mM}$ Citrate buffer pH 6.02 & 60 \\
\hline
\end{tabular}


Table 2 Distribution of histological findings found in primary, recurrent tumors and those associated with NBCCS
Note: -, absent; +, present; $\mathrm{P}$, primary tumor; $\mathrm{R}$, recurrent tumor; SCBCN, tumor associated with nevoid basal cell carcinoma syndrome

\begin{tabular}{|c|c|c|c|c|c|c|}
\hline Case & $\begin{array}{l}\text { Group of } \\
\text { lesions }\end{array}$ & $\begin{array}{l}\text { Subpithelial } \\
\text { splits }\end{array}$ & $\begin{array}{l}\text { Epithelial } \\
\text { buds }\end{array}$ & $\begin{array}{l}\text { Satellite } \\
\text { cysts }\end{array}$ & $\begin{array}{l}\text { Significant } \\
\text { inflamation }\end{array}$ & $\begin{array}{l}\text { Discret } \\
\text { inflamation }\end{array}$ \\
\hline 1 & $\mathrm{P}$ & - & + & + & - & + \\
\hline 2 & $\mathrm{P}$ & - & + & - & - & - \\
\hline 3 & $\mathrm{P}$ & - & + & + & - & + \\
\hline 4 & $\mathrm{P}$ & - & + & - & - & - \\
\hline 5 & $\mathrm{P}$ & - & - & - & - & + \\
\hline 6 & $\mathrm{P}$ & - & - & - & - & + \\
\hline 7 & $\mathrm{P}$ & + & - & - & + & - \\
\hline 8 & $\mathrm{P}$ & - & + & + & - & - \\
\hline 9 & $\mathrm{P}$ & + & + & + & + & - \\
\hline 10 & $\mathrm{P}$ & + & - & + & + & - \\
\hline 11 & $\mathrm{R}$ & - & - & - & - & + \\
\hline 12 & $\mathrm{R}$ & - & - & - & - & - \\
\hline 13 & $\mathrm{R}$ & - & - & + & - & - \\
\hline 14 & $\mathrm{R}$ & + & - & + & - & + \\
\hline 15 & $\mathrm{R}$ & + & - & + & - & - \\
\hline 16 & $\mathrm{R}$ & - & - & + & - & - \\
\hline 17 & $\mathrm{R}$ & - & - & - & - & - \\
\hline 18 & $\mathrm{R}$ & - & - & - & + & - \\
\hline 19 & $\mathrm{R}$ & - & - & + & - & - \\
\hline 20 & $\mathrm{R}$ & - & + & - & + & - \\
\hline 21 & SCBCN & - & + & + & - & - \\
\hline 22 & SCBCN & - & + & + & + & - \\
\hline 23 & SCBCN & + & + & + & - & - \\
\hline 24 & SCBCN & - & + & + & - & + \\
\hline 25 & SCBCN & - & + & - & - & + \\
\hline
\end{tabular}

tumors, 2/10; recurrent tumors, 4/10; syndrome tumors, 1/5) and 19 (primary tumors, 9/10; recurrent tumors, 9/10; syndrome tumors, 5/5) were immunoreactive in mostly cases of KOTs (Fig. 1). However, CKs 7, 8 and 10 were negative in all samples. The immunohistochemical results are summarized in Table 3.

Immunostaining for CK13 was observed in 17 (68\%) cases, particularly involving intermediate and superficial layers, regardless the subjacent inflammatory process, subepithelial splits or thickness of cystic epithelium. Five from these cases showed immunostaining for this $\mathrm{CK}$ in satellite cysts, which was seen on peripheral cells or on keratin layers. A few cases, within the same tumor, immunolabeling of CK 13 was seen as clusters of cells or isolated cells. In those tumors exhibiting epithelial buds, the expression of CK 13 was lost, being most often seen on upper and superficial cells.

KOTs showed CK 14 in all epithelial layers, including areas where inflammation and subepithelial splits were present, although this finding was not evident in two cases of recurrent tumors. In addition, other areas within the same tumor showed loss of marking, preserving the basal layer. A few cases, within the same tumor, showed expression of CK 14 as clusters of cells or isolated cells. On the other hand, from nine cases exhibiting satellite cysts, CK14 was also present, but its expression was variable. In those tumors exhibiting epithelial remnants, this CK was present strongly.

Seven cases (28\%) were found to be immunopositive for CK 18, with its expression being observed particularly in the basal layer, corresponding to primary, recurrent tumors and those associated with NBCCS. However, all epithelial layers were stained in three cases, including areas with inflammation.

With respect to CK 19, only one case did not show immunostaining. This protein was particularly immunoreactive in all epithelial layers, accounting for $13(52 \%)$ cases. However, it involved only the intermediate and superficial layers in 10 cases $(40 \%)$. Only one case showed the basal and intermediate layers positive for CK 19. In those cases exhibiting significant presence of inflammatory infiltrate, all epithelial layers were immunoreactive. This $\mathrm{CK}$ was present in nine cases exhibiting satellite cysts, being seen both peripheral cells and keratin layers. 

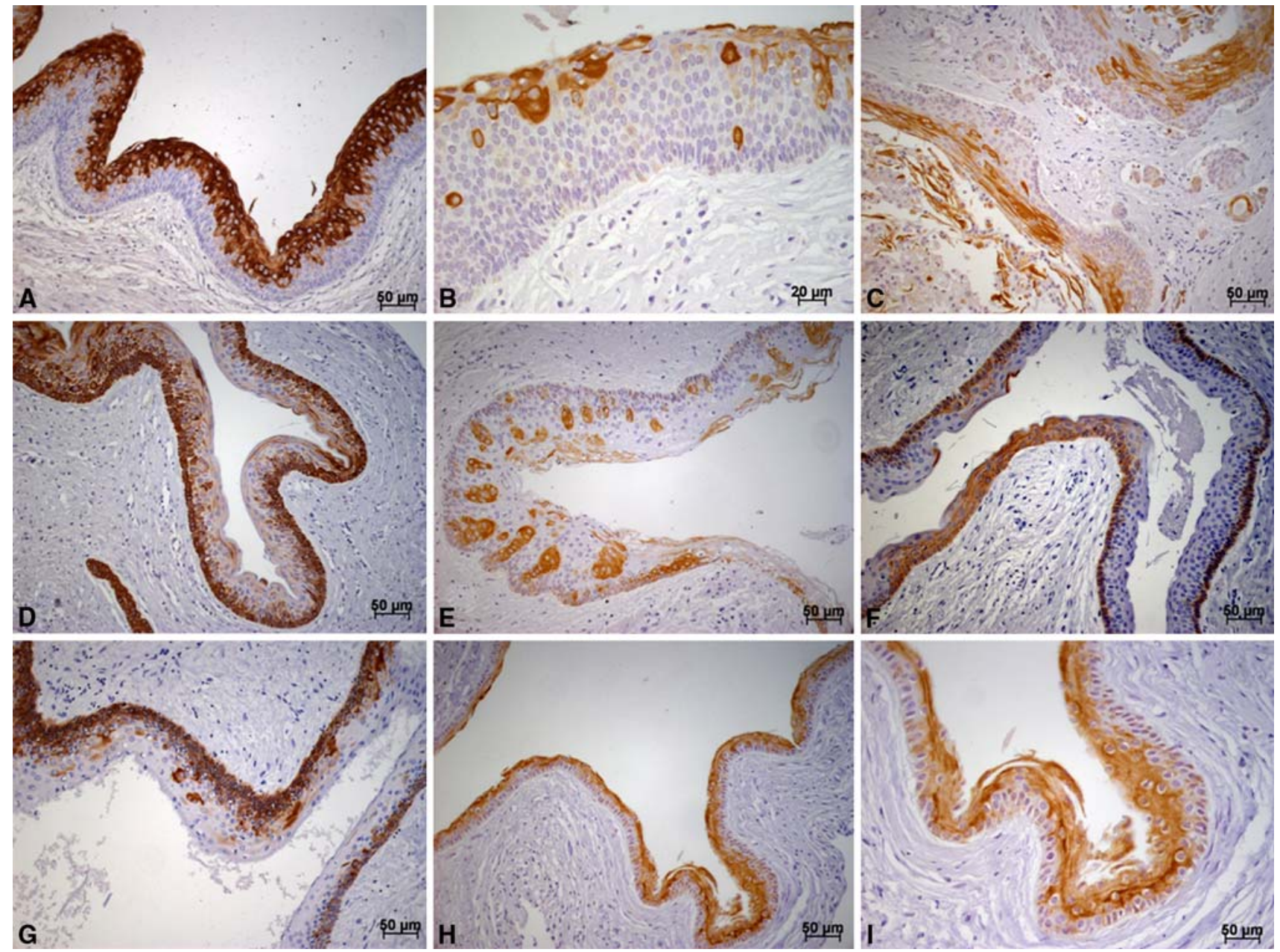

Fig. 1 Immunohistochemical staining of keratocystic odontogenic tumors. a Strong expression of CK 13 in intermediate and superficial epithelial layers (Streptavidin-biotin complex). b Expression of CK 13 in upper layers and isolated cells (Streptavidin-biotin complex). c Expression of CK 13 seen in satellite cysts (Streptavidin-biotin complex). d CK 14 is expressed in all epithelial layers on the lefthand side, and other areas within the same tumor show loss of immunostaining with preservation of basal/suprabasal epithelial cells

\section{Discussion}

The expression of different cytokeratins depends on the cell differentiation, status of development, and type of epithelium (Chu and Weiss 2002; Moll et al. 1982; Moll et al. 2008). When the keratinocyte cell migration to upper layers of the epithelium occurs, the cells undergo a maturation process, detectable through altered cytokeratin expression (Hormia et al. 1987). Therefore, the study focusing on epithelial differentiation of KOT may be performed by immunohistochemistry through the analysis of intermediate filaments.

CK 10 is associated with terminal differentiation and keratinization (Koch and Roop 2004; Moll 1998; Stoll et al. 2005), and has been detected on the lining of
Epithelial remnants display strong expression (Streptavidin-biotin complex). e Expression of CK 14 in group of epithelial cells (Streptavidin-biotin complex). f, g Heterogenous expression of CK 18 reaching basal and upper layers as well as cluster of cells (Streptavidin-biotin complex). h Expression of CK 19 reaching all cystic lining (Streptavidin-biotin complex). i High-power view showing heterogenous expression of CK 19 mainly reaching intermediate and superficial layers (Streptavidin-biotin complex)

odontogenic cysts including KOTs (Stoll et al. 2005; Silva et al. 2002). In contrast, our results showed absence of immunostaining for this CK in all analyzed cases. This may be attributable to difficulty in the cell maturation. Despite these results using immunohistochemistry, other authors have issued similar reports. Hormia et al. (1987), in a study with monoclonal antibodies, found absence of immunostaining for specific keratins for keratinized epithelium (CK 1, 9 and 10/11); according to those authors, this result was caused by a pseudokeratinization of the KOT epithelium. In 2000, August et al. showed that after decompression and cystectomy, KOTs dedifferentiate and lose CK 10. In addition, it is important to state that CK 10 is not a typical intermediate filamentous found in odontogenic epithelium (Crivelini et al. 2003) . 
Table 3 Expression of cytokeratins according to epithelial layers and primary, recurrent tumors and those associated with NBCCS

\begin{tabular}{|c|c|c|c|c|c|}
\hline Case & Group of lesions & CK 13 & CK 14 & CK 18 & CK 19 \\
\hline 1 & $\mathrm{P}$ & - & $\mathrm{B}, \mathrm{I}, \mathrm{S}$ & - & $\mathrm{I}, \mathrm{S}$ \\
\hline 2 & $\mathrm{P}$ & - & $\mathrm{B}, \mathrm{I}, \mathrm{S}$ & B & $\mathrm{I}, \mathrm{S}$ \\
\hline 3 & $\mathrm{P}$ & $\mathrm{I}, \mathrm{S}$ & $\mathrm{B}, \mathrm{I}, \mathrm{S}$ & $\mathrm{B}, \mathrm{I}, \mathrm{S}$ & $\mathrm{B}, \mathrm{I}, \mathrm{S}$ \\
\hline 4 & $\mathrm{P}$ & - & $\mathrm{B}, \mathrm{I}, \mathrm{S}$ & - & $\mathrm{B}, \mathrm{I}, \mathrm{S}$ \\
\hline 5 & $\mathrm{P}$ & $\mathrm{I}, \mathrm{S}$ & $\mathrm{B}, \mathrm{I}, \mathrm{S}$ & - & $\mathrm{I}, \mathrm{S}$ \\
\hline 6 & $\mathrm{P}$ & $\mathrm{I}, \mathrm{S}$ & $\mathrm{B}, \mathrm{I}, \mathrm{S}$ & - & $\mathrm{B}, \mathrm{I}, \mathrm{S}$ \\
\hline 7 & $\mathrm{P}$ & $\mathrm{I}, \mathrm{S}$ & $\mathrm{B}, \mathrm{I}, \mathrm{S}$ & - & $\mathrm{B}, \mathrm{I}, \mathrm{S}$ \\
\hline 8 & $\mathrm{P}$ & $\mathrm{I}, \mathrm{S}$ & $\mathrm{B}, \mathrm{I}, \mathrm{S}$ & - & $\mathrm{B}, \mathrm{I}, \mathrm{S}$ \\
\hline 9 & $\mathrm{P}$ & $\mathrm{I}, \mathrm{S}$ & $\mathrm{B}, \mathrm{I}, \mathrm{S}$ & - & $\mathrm{B}, \mathrm{I}, \mathrm{S}$ \\
\hline 10 & $\mathrm{P}$ & $\mathrm{I}, \mathrm{S}$ & $\mathrm{B}, \mathrm{I}, \mathrm{S}$ & - & - \\
\hline 11 & $\mathrm{R}$ & $\mathrm{I}, \mathrm{S}$ & $\mathrm{B}, \mathrm{I}, \mathrm{S}$ & - & $\mathrm{B}, \mathrm{I}, \mathrm{S}$ \\
\hline 12 & $\mathrm{R}$ & - & $\mathrm{B}, \mathrm{I}, \mathrm{S}$ & B & $\mathrm{I}, \mathrm{S}$ \\
\hline 13 & $\mathrm{R}$ & - & $\mathrm{B}, \mathrm{I}$ & $\mathrm{B}, \mathrm{I}, \mathrm{S}$ & $\mathrm{B}, \mathrm{I}, \mathrm{S}$ \\
\hline 14 & $\mathrm{R}$ & $\mathrm{I}, \mathrm{S}$ & $\mathrm{B}, \mathrm{I}, \mathrm{S}$ & - & $\mathrm{B}, \mathrm{I}, \mathrm{S}$ \\
\hline 15 & $\mathrm{R}$ & $\mathrm{I}, \mathrm{S}$ & $\mathrm{B}, \mathrm{I}, \mathrm{S}$ & $\mathrm{B}, \mathrm{I}, \mathrm{S}$ & $\mathrm{I}, \mathrm{S}$ \\
\hline 16 & $\mathrm{R}$ & $\mathrm{I}, \mathrm{S}$ & $\mathrm{B}, \mathrm{I}, \mathrm{S}$ & - & $\mathrm{B}, \mathrm{I}$ \\
\hline 17 & $\mathrm{R}$ & - & $\mathrm{B}, \mathrm{I}$ & B & $\mathrm{I}, \mathrm{S}$ \\
\hline 18 & $\mathrm{R}$ & - & $\mathrm{B}, \mathrm{I}, \mathrm{S}$ & - & $\mathrm{B}, \mathrm{I}, \mathrm{S}$ \\
\hline 19 & $\mathrm{R}$ & $\mathrm{I}, \mathrm{S}$ & $\mathrm{B}, \mathrm{I}, \mathrm{S}$ & - & $\mathrm{B}, \mathrm{I}, \mathrm{S}$ \\
\hline 20 & $\mathrm{R}$ & $\mathrm{I}, \mathrm{S}$ & $\mathrm{B}, \mathrm{I}, \mathrm{S}$ & - & $\mathrm{B}, \mathrm{I}, \mathrm{S}$ \\
\hline 21 & $\mathrm{SCBCN}$ & - & $\mathrm{B}, \mathrm{I}, \mathrm{S}$ & B & $\mathrm{I}, \mathrm{S}$ \\
\hline 22 & SCBCN & $\mathrm{I}, \mathrm{S}$ & $\mathrm{B}, \mathrm{I}, \mathrm{S}$ & - & $\mathrm{B}, \mathrm{I}, \mathrm{S}$ \\
\hline 23 & $\mathrm{SCBCN}$ & $\mathrm{I}, \mathrm{S}$ & $\mathrm{B}, \mathrm{I}, \mathrm{S}$ & - & $\mathrm{I}, \mathrm{S}$ \\
\hline 24 & SCBCN & $\mathrm{I}, \mathrm{S}$ & $\mathrm{B}, \mathrm{I}, \mathrm{S}$ & - & $\mathrm{I}, \mathrm{S}$ \\
\hline 25 & SCBCN & $\mathrm{I}, \mathrm{S}$ & B,I,S & - & $\mathrm{B}, \mathrm{I}, \mathrm{S}$ \\
\hline
\end{tabular}

Note: -, negative expression; B, expression in basal epithelial cells; I, expression in epithelial cell of the intermediate or upper cells; $\mathrm{S}$, expression in superficial epithelial layers. $\mathrm{P}$, primary tumor; $\mathrm{R}$, recurrent tumor; SCBCN, tumor associated with nevoid basal cell carcinoma syndrome

CK 13 is present in odontogenic epithelium. It has been related to squamous differentiation, and located on suprabasal layers (Hormia et al. 1987; Meara et al. 2000; Silva et al. 2002; Santos et al. 2003). This immunolocalization was also observed in this study, but superficial layers and isolated cells were also immunolabeled. Despite the different immunolabellings on different epithelial layers, using the same methodology, Silva et al. (2002) observed the expression of CK 13 on the superficial layers and Meara et al. (2000) observed this protein on upper cells within the intermediate layer with similar staining pattern regarding syndromic patients and non-syndromic ones. In addition, other odontogenic lesions as radicular cysts and denigerous cysts also showed positive staining for this protein (Stoll et al. 2005). Thus, these findings seem to indicate a complex maturation in KOTs (Fig. 1).

CK 14 is the main intermediate filament observed in the dental lamina, in the reduced enamel epithelium, in almost all cells of the enamel organ, and odontogenic tumors as ameloblastomas (Crivelini et al. 2003). Our data showed immunolabelling of this protein in all cases, including, especially, basal, intermediate and superficial layers. This immunolocalization was seen in those areas exhibiting subepithelial splits and inflammation, although in some cases this was not seen. Silva et al. (2002) and Vargas et al. (2007) showed that CK14 expression was restricted to basal cells. Although some tumors studied in this series also showed basal cells stained, the immunolabeling was not restricted to basal layer. In addition, Silveira et al. (2006) observed immunolabelling for CK 14 in the adjacent epithelium to oral squamous cell carcinomas, and labelling involving only the basal layer of these epithelia in more distant areas of the tumors. Taken together, these results seem to be controversial, and suggest instability in the structural integrity of the KOT as well as altered epithelial differentiation.

The inflammatory infiltrate may induce modifications in the expression of CKs on the epithelium lining, as shown in lesions of actinic cheilitis (Santos et al. 2003), periodontopathies (Mackenzie and Gao 1993), supurative hydranite (Kurzen et al. 1999; Wang et al. 2007), inflammated gastrical mucosa (Kurokawa et al. 2002), erythematous lupus (Gürbüz and Köse 2006), and this may be due to the production of inflammatory cytokines (Silva et al. 2002). In this study, this aspect was also evidenced in KOT regarding CK 14.

In contrast to previous authors (Gao et al. 1989; Meara et al. 2000), our study showed expression of CK 18 in KOT. According to Crivelini et al. 2003, CK 18 is not evident in odontogenic epithelium, however, a few cases of glandular odontogenic cyst have shown the opposite (Pires et al. 2004). These distinct results may be attributable to the heterogeneity observed in the altered expression pattern of cytokeratins in KOT. Moreover, CK 8/18 has been found in oral leukoplakia with dysplasia and oral squamous cell carcinoma (Fillies et al. 2007).

CK 19 is detected in simple epithelium and basal cells present in non keratinized epithelium (Crivelini et al. 2003; Moll et al. 1982; Stoll et al. 2005). In the present study, the CK19 was strongly expressed in almost $96 \%$ of KOTs, affecting mainly suprabasal and intermediate layer cells. The absence of strong expression of CK 19 in basal cells may be due to the fact that stem cells or progenitor cells may not be sufficiently detected by this CK, but enough to maintain the phenotype of odontogenic epithelial differentiation. In addition, a study by Stoll et al. (2005) showed CK 19 in radicular cysts and dentigerous cysts, with a completely absent staining in KOTs. These conflicting findings may be due to the different clones used in both studies, and reflect a heterogeneous pattern of immunolabelling in KOTs. 
According to Crivelini et al. (2003), ameloblastomas with areas exhibiting metaplastic squamous cells show expression of CK 19 and 13. Similarly, our study showed that both cytokeratins are present in KOTs, indicating that these lesions share the same origin, as CKs 19 and 13 are components of dental lamina. However, this suggests an altered squamous differentiation. In addition, our results showed that areas exhibiting strong inflammation, showed positivity for CK 19 involving all cystic epithelium, as seen in those cases marked with CK14. This may also be related to the production of interleukins, as previously discussed. It is important to state that CK 19 is detected in the epithelium close to squamous cell carcinomas, suggesting its use as a pivotal biologic agent of malignant progression (Xu et al. 1995; Crivelini et al. 2003; Silveira et al. 2006). On the other hand, KOTs show high levels of the protein $\Delta \mathrm{Np} 63$, which reflects the presence of immature keratinocytes, with high proliferative capacity (Gurgel et al. 2008). This aspect has been confirmed by the staining for CK 16 and the protein Ki-67(Gurgel et al. 2008; Gao et al. 1989; Hormia et al. 1987).

With respect to CKs 7 and 8, we did not detect immunolabelling of these proteins. These CKs are commonly expressed on simple epithelia (Barak et al. 2004; Moll et al. 1982; Moll et al. 2008). Nevertheless, they have been showed in dental organ and odontogenic lesions in variable proportions (García et al. 2009; Hormia et al. 1987; Meara et al. 2000; Matthews et al. 1988; Pires et al. 2004; Stoll et al. 2005).

The altered profile of CKs expression studied seems to be related to the differentiation and maturation status of the cystic epithelium of the KOTs, and this is not distinct when primary and recurrent tumors, and those associated with SCBNN are compared.

Acknowledgments This work was supported by the FAPESB (The State of Bahia Research) Grants n. 122/07.

\section{References}

Ahn SG, Lim YS, Kim DK et al (2004) Nevoid basal cell carcinoma syndrome: a retrospective analysis of 33 affected Korean individuals. Int J Oral Maxillofac Surg 33:458-462

August M, Faquin WC, Troulis M et al (2000) Differentiation of odontogenic keratocysts from nonkeretinizing cysts by use of fine-needle aspiration biopsy and cytokeratin-10 staining. J Oral Maxillofac Surg 58:935-940

Barak V, Goike H, Panaretakis KW et al (2004) Clinical utility of cytokeratin as tumor markers. Clinical Biochem 37:529-540

Chu PG, Weiss LM (2002) Keratin expression in human tissues and neoplasms. Histopathology 40:403-439

Cooper D, Schemer A, Sun TT (1985) Classification of human epithelial and their neoplasms using monoclonal antibodies to keratins: strategies, applications and limitations. Lab Invest $52: 243-256$
Crivelini MM, Araújo VC, Sousa SOM et al (2003) Cytokeratins in epithelia of odontogenic neoplasms. Oral Disease 9:1-6

El-Hajj G, Anneroth G (1996) Odontogenic keratocyst- a retrospective clinical and histologic study. Int J Oral Maxillofac Surg 25:124-129

Fillies T, Jogschies M, Kleinheinz J et al (2007) Cytokeratin alteration in oral leukoplakia and oral squamous cell carcinoma 18:639-43

Gao Z, Mackenzie IC, Cruchley AT et al (1989) Cytokeratin expression of the odontogenic epithelia in dental follicles and developmental cysts. J Oral Pathol Med 18:63-67

García CC, Diago MP, Mira BG et al (2009) Expression of cytokeratins in epithelized periapical lesions. Oral Surg Oral Med Oral Pathol Oral Radiol Endod 107:43-46

Gomez RS, Marco L (2005) Possible molecular approach to the treatment of odontogenic keratocyst. Oral Surg Oral Med Oral Pathol Oral Radiol Endod 99:527-528

González-Alva P, Tanaka A, Oku Y et al (2008) Keratocystic odontogenic tumor: a retrospective study of 183 cases. J Oral Sci 50:205-212

Gürbüz Y, Köse N (2006) Cytokeratin expression patterns of gastric carcinomas according to Lauren and Goseki classification. Appl Immunohistochem Mol Morphol 14:303-308

Gurgel CA, Ramos EA, Azevedo RA et al (2008) Expression of Ki67, p53 and p63 proteins in keratocyst odontogenic tumours: an immunohistochemical study. J Mol Histol 39:311-316

Hardcastle Z, Hui CC, Sharpe PT (1999) The SHH signaling pathway in early tooth development. Cell Mol Biol 45:567-568

Hormia M, Ylipaavalniemi P, Virtanen I (1987) Expression of cytokeratins in odontogenic jaw cysts: Monoclonal antibodies reveal distinct variation between different cyst types. J Oral Pathol 16:338-346

Koch PJ, Roop DR (2004) The role of keratins in epidermal development and homeostasis-going beyond the obvious. J Invest Dermatol 123:973-974

Kolar Z, Geierova M, Bouchal J et al (2006) Immunohistochemical analysis of the biological potential of odontogenic keratocysts. J Oral Pathol Med 35:75-80

Kurokawa I, Nishijima S, kusumoto K et al (2002) Immunohistochemical study of cytokeratins in hidradenitis suppurativa (acne inversa). J Int Med Res 30:131-136

Kurzen H, Jung EG, Hartschuh W et al (1999) Forms of epithelial differentiation of draining sinus in acne inversa (hidradenitis suppurativa). Br J Dermatol 141:231-239

Lam KY, Chan ACL (2000) Odontogenic keratocyst: a clinicopathological study in Hong Kong Chinese. Laryngoscope 110:13281332

Mackenzie IC, Gao Z (1993) Patterns of cytokeratin expression in the epithelia of inflamed human gingiva and periodontal pockets. J Periodontal Res 28:49-59

Matthews JB, Mason GI, Browne RM (1988) Epithelial cell markers and proliferating cells in odontogenic jaw cysts. J Pathol 156:283-290

Meara JM, Shah SS, Cunningham MJ (2000) Cytokeratin expression in the odontogenic keratocyst. Int $\mathbf{J}$ Oral Maxillofac Surg $58: 862-865$

Meningaud JP, Oprean N, Pitak Armnop P et al (2006) Odontogenic cysts: a clinical study of 695 cases. J Oral Sci 48:59-62

Moll R (1998) Cytokeratins as markers of differentiation in the diagnosis of epithelial tumors. Subcell Biochem 31:205-262

Moll R, Franke WW, Schiller DL (1982) The catalog of human cytokeratins: patterns of expression in normal epithelial, tumors and cultured cells. Cell 31:11-24

Moll R, Divo M, Langbein L (2008) The human keratins: biology and pathology. Histochem Cell Biol 129:705-733 
Myoung H, Hong SP, Hong SD et al (2001) Odontogenic keratocyst: review of 256 cases for recurrence and clinicopathologic parameters. Oral Surg Oral Med Oral Pathol Oral Radiol Endod 91:328-333

Ochsenius G, Escobar E, Godoy L et al (2007) Odontogenic cysts: analysis of 2, 944 cases in Chile. Med Oral Patol Oral Cir Bucal 12:E85-E91

Pires FR, Chen SY, da Cruz Perez DE et al (2004) Cytokeratin expression in central mucoepidermoid carcinoma and glandular odontogenic cyst. Oral Oncol 40:545-551

Santos JN, Sousa SOM, Nunes FD et al (2003) Altered cytokeratin expression in actinic cheilitis. J Cutan Pathol 30:237-241

Shuler CF, Shriver BJ (1987) Identification of intermediate filament keratin in parakeratinized odontogenic keratocyst. Oral Surg Oral Med Oral Pathol 64:439-444

Silva MJA, Sousa SOM, Côrrea L et al (2002) Immunohistochemical study of the orthokeratinized odontogenic cyst: a comparison with the odontogenic keratocyst. Oral Surg Oral Med Oral Pathol Oral Radiol Endod 94:732-737
Silveira EJD, Barros SSLV, Amorim RFB et al (2006) Cytokeratin profile in mucoepidermoid carcinoma is not related to its histological grading of malignancy. Exp Mol Pathol 81:72-76

Stoll C, Stollenwerk C, Riediger D et al (2005) Cytokeratin expression patterns for distinction of Odontogenic keratocysts from dentigerous and radicular cyst. J Oral Pathol Med 34:558-564

Tortorici S, Amodio E, Massenti MF et al (2008) Prevalence and distribution of odontogenic cysts in Sicily. J Oral Sci 50:15-18

Vargas PA, da Cruz Perez DE, Mata GM et al (2007) Fine needle aspiration cytology as an additional tool in the diagnosis of odontogenic keratocyst. Cytopathology 18:361-366

Wang L, Srinivasan S, Theiss AL et al (2007) Interleukin-6 induces keratin expression in intestinal epithelial cells: potential role of keratin-8 in interleukin-6-induced barrier function alterations. J Biol Chem 282:8219-8227

Xu XC, Lee JS, Lippman SM et al (1995) Increased expression of cytokeratins CK8 and CK19 is associated with head and neck carcinogenesis. Cancer Epidemiol Biomarkers Pre 4:871-876 